\title{
Bacterial contamination of blood and blood components in a tertiary hospital setting in Nigeria
}

\author{
Rahman A Bolarinwa ${ }^{1}$, Oladipo A Aboderin², Babatunde W Odetoyin ${ }^{2}$, Aramide B. Adegunloye ${ }^{3}$ \\ 'Department of Haematology and Immunology, College of Health Sciences, \\ Obafemi Awolowo University, Ile-Ife, Nigeria \\ ${ }^{2}$ Department of Medical Microbiology and Parasitology, College of Health Sciences, \\ Obafemi Awolowo University, Ile-Ife, Nigeria \\ ${ }^{3}$ Department of Haematology and Blood Transfusion, \\ Obafemi Awolowo University Teaching Hospitals Complex, Ile-Ife, Nigeria.
}

doi: 10.3396/ijic.V7i1.004.11

\begin{abstract}
Screening donors has practically eliminated viral pathogens in blood for transfusion; however, transfusion-associated bacterial sepsis remains an important health-care concern. Currently, it is the most frequently reported cause of transfusion-related fatality from infection. The aim of this study was to determine the prevalence and type of bacterial contamination in donor blood and/or blood products, in a semi-urban university teaching hospital in Nigeria.

The study was carried out at the Obafemi Awolowo University Teaching Hospitals Complex, Ile-lfe, Nigeria over a five-month period (May to September 2009). A total of 162 units of screened blood and blood products consisting of $160(98.7 \%)$ refrigerated packed cells/whole blood and two (1.3\%) platelet concentrates were randomly sampled following aseptic procedure. Samples were incubated at $37^{\circ} \mathrm{C}$ for up to 7 -days in Brain Heart Infusion broth. Isolates were identified by standard microbiologic techniques, and their resistance to selected antimicrobial agents was tested by disc diffusion.
\end{abstract}

\section{Correspondence}

Dr. Oladipo A. Aboderin, Senior Lecturer, Department of Medical Microbiology and Parasitology, College of Health Sciences, Obafemi Awolowo University, Ile-Ife, Nigeria.

Telephone: +2348036706730

E-mail: aaboderin@oauife.edu.ng, diipo_aboderin@yahoo.com 
Overall prevalence of bacterial contamination in donated blood bank refrigerated blood was $8.8 \%$. The organisms isolated were Gram-positive, namely, Staphylococcus aureus, coagulase negative Staphylococcus, Bacillus sp, and Listeria sp. Antibiotic resistances ranged from $29 \%$ to $100 \%$.

Bacterial contamination of blood and blood components for transfusion is common in Nigeria and is a potential risk for hospital acquired infection.

\section{Key words}

Bacterial contaminants, hospital-acquired infection, blood/blood components.

\section{Introduction}

The transmission of infectious agents including bacterial and viral organisms through blood and blood products has been long established. Recipients of donor blood have been known to acquire human immunodeficiency virus (HIV), Hepatitis B virus (HBV) and Hepatitis C virus (HCV), human T-cell lymphotrophic virus (HTLV), Treponema pallidum and Mycobacterium tuberculosis through blood transfusion; ${ }^{1,2}$ while cytomegalovirus (CMV) infection is a serious risk in bone marrow and organ transplant patients. ${ }^{3}$ Over the years, improved donor screening almost eliminated HIV, HBV and HCV from the United States blood supply. ${ }^{4}$ In Nigeria like other developing countries, these transfusiontransmissible infections still pose a threat; several reports have documented transmissible pathogens (HIV, HBV, HCV, and Treponema pallidum) in blood donors. ${ }^{5,6}$ Considerable efforts (and national policies) directed towards reducing transmissible pathogens (improved donor selection and newer screening techniques) have yielded a major reduction of these agents in advanced countries. ${ }^{7-9}$ However transfusiontransmitted bacterial infection was identified as the commonest cause of complications associated with transfusion, ${ }^{10}$ numerous studies have demonstrated that contaminating bacteria (usually skin flora) can be cultured from approximately 1/3000 platelet units. ${ }^{11}$ According to data from SHOT (Serious Hazards Of Transfusion), the haemovigilance system in the UK, in 1995-2006, there were 33 cases of post-transfusion bacterial sepsis, 29 due to transfusion of platelets and four to red cell concentrates. No deaths were caused by Hepatitis viruses, HIV or HTLV-I. Eight deaths were caused by bacterial contamination of transfused platelets. In the United States, bacterial contamination of blood and blood products accounted for $15.9 \%$ of all transfusion related fatalities, indeed it is considered the second commonest cause of death from transfusion after clerical errors. ${ }^{12}$ In Ghana, $9-17.5 \%$ of donor bloods were contaminated by bacteria. ${ }^{13,14}$ The bacteria transmissible in blood and blood components include Gram negative bacteria- Klebsiella pneumoniae, Escherichia coli, Yersinia enterocolitica, Pseudomonas fluorescens, Pseudomonas aeruginosa and Gram positive bacteria including Bacillus species and Staphylococcus aureus. ${ }^{13-14}$ Arguably, bacterial contamination of whole blood and its various components can occur at several points including production of blood bags, donor venepuncture, blood donor bacteraemia, blood component separation or at the time of transfusion. ${ }^{15}$

In Nigeria, there are no reports of bacterial contamination of blood and blood products, despite the high demand for these created by children with severe anaemia secondary to malaria, victims of road traffic accidents or in obstetrics emergencies amongst many other indications. We hypothesized that bacterial contamination of donor blood is a significant but overlooked health hazard that may lead to hospitalacquired infection in recipients. Thus, we sought to determine the prevalence of bacterial contamination in our donor blood and blood components, identify the organisms involved and determine the antibiotic susceptibility pattern of any isolated microorganisms with a view to instituting appropriate infection control and preventive interventions. 


\section{Materials and methods}

\section{Study site and design}

This was a cross-sectional study carried out at the Obafemi Awolowo University Teaching Hospital Complex (OAUTHC), lle-Ife, over a five month period (May-September 2009). OAUTHC is a 600-bedded tertiary hospital centre affiliated to the Obafemi Awolowo University located in a town of about 750,000 in Southwest Nigeria, and provides health care services to people from five surrounding states and referrals from other parts of the country. Each year about 3000 bags of whole blood are donated. 51.7\% constitute family replacement donation and only $2.5 \%$ come from voluntary non-remunerated donors. The remainder $(45.8 \%)$ is from paid commercial donors. All donors are screened for HIV, HBV, HCV and syphilis before blood collection. Blood collection is anchored by a trained blood donor organizer supported by phlebotomists dedicated to the bleeding room. Blood/ blood components are collected in citrate-phosphatedextrose-adenine (CPD-A) blood-bags after disinfecting the phlebotomy site with $70 \%$ ethanol following a standard procedure including hand hygiene.

\section{Sampling}

We randomly sampled 162 units representing $5 \%$ of annual donations. The blood samples were obtained from screened, stored whole blood, packed cells, fresh frozen plasma (ready for use) and platelet concentrate. The procedures were undertaken with attention to aseptic and safety precautions by one of us (RAB), who is a consultant Haematologist. All expired blood and blood products were excluded. Each unit of blood was mixed before sampling and the tubing was cleaned with $70 \%$ alcohol and cut with sterile scissors to remove any clotted blood and also allowing some mixed blood to slip out of the blood bag. Three knots were made in each bag tubing and recleaned with $70 \%$ ethanol; $3 \mathrm{mls}$ of blood was drawn from the closest end to the bag with a sterile syringe and needle and dispensed into $15 \mathrm{mls}$ of Brain-Heart Infusion (BHI) broth. The specimens were sent to the Microbiology laboratory for isolation, identification and susceptibility testing.

\section{Bacterial isolation and identification}

The broths were incubated at $37^{\circ} \mathrm{C}$ up to 7 days before they were discarded. After overnight incubation, sterile loopfuls of broth were sub-cultured on to blood agar and MacConkey agar plates and incubated aerobically for $18-24$ hours at $37^{\circ} \mathrm{C}$. The identities of bacteria growing on the culture plates were determined by colonial morphology, Gram and spore stains; as well as standard biochemical tests.

\section{Antibiotic susceptibility testing}

Susceptibility to antimicrobial agents was tested by the disc diffusion technique according to the guidelines by the Clinical and Laboratory Standards Institute $(\mathrm{CLSI}){ }^{16} \quad$ The antibiotic discs used were ampicillin $10 \mu \mathrm{g}$; cotrimoxazole, $25 \mu \mathrm{g}$; erythromycin $15 \mu \mathrm{g}$; penicillin 10 units; tetracycline $30 \mu \mathrm{g}$; ciprofloxacin, $5 \mu \mathrm{g}$; gentamicin, $10 \mu \mathrm{g}$; ceftriaxone $30 \mu \mathrm{g}$ (Remel, Lenexa, Kansas) and rifampicin $5 \mu \mathrm{g}$ (Oxoid). The discs were placed on to the surface of inoculated MuellerHinton agar plates by an auto dispenser (Remel). After overnight incubation, the inhibition zone diameters were measured to the nearest millimeter, and isolates were classified as susceptible, intermediate, or resistant according to CLSI-specified interpretive criteria. Intermediate and resistant strains were further grouped together in the resistant group for analysis. E. coli ATCC 25922 was used as the control strain.

\section{Ethical considerations}

The study received ethical clearance from the Ethical committee of the Obafemi Awolowo University Teaching Hospital, Ile-Ife, Nigeria.

\section{Results}

Over the study period, 162 randomly selected units of blood (160 refrigerated packed cells/whole blood and two platelet concentrates) were tested and $14(8.8 \%)$ were found to be contaminated. All the contaminated samples were of whole blood. Table I shows the contaminated blood bags and the identified organisms.

All the bacterial species isolated were Gram positive, namely Staphylococcus aureus, coagulase-negative Staphylococcus, Bacillus sp and Listeria sp (Table I). The bacterial isolates showed diverse resistance patterns as shown in Table II. Resistance to all the antibiotics 
Table I: Isolated microorganisms and time of storage

Microorganism

Time of storage

Staphylococcus aureus

Day 0

Staphylococcus aureus

Day 14

Staphylococcus aureus

Day 14

Listeria spp

Day 8

Listeria spp

Day 6

Listeria spp

Day 21

Bacillus spp

Day 1

Bacillus spp

Day 1

Coagulase-negative staphylococci

Day 1

Bacillus spp

Day 3

Bacillus spp

Day 0

Staphylococcus aureus

Day 12

Coagulase-negative staphylococci

Day 0

Coagulase-negative staphylococci

Day 5

Table II: Antibiotic resistance pattern of the bacteria isolated from contaminated samples $:$ numbers $=$ number resistant

\begin{tabular}{lrrrrrrrrrr}
\multicolumn{1}{c}{ Isolates } & Number tested & AMP & COT & ERY & PEN & TET & RIF & CIP & GEN & CEF \\
\hline S. aureus & 4 & NT & 3 & 2 & 4 & NT & 0 & 4 & 1 & 0 \\
\hline CoNS & 3 & NT & 3 & 3 & 3 & NT & 1 & 3 & 1 & 3 \\
\hline Bacillus spp & 4 & 3 & 3 & 3 & 4 & 4 & 3 & 2 & NT & NT \\
\hline Listeria spp & 3 & 3 & 3 & 3 & 3 & 3 & 3 & 3 & NT & NT \\
\hline Total & 14 & $6 / 7$ & $12 / 14$ & $11 / 14$ & $14 / 14$ & $7 / 7$ & $7 / 14$ & $12 / 14$ & $2 / 7$ & $3 / 7$ \\
\hline
\end{tabular}

$\mathrm{AMP}=$ ampicillin; $\mathrm{COT}=$ cotrimoxazole; $\mathrm{ERY}=$ erythromycin; $\mathrm{PEN}=$ penicillin; $\mathrm{TET}=$ tetracycline;

$\mathrm{RIF}=$ rifampicin; $\mathrm{CIP}=$ ciprofloxacin; $\mathrm{CEF}=$ ceftriaxone; $\mathrm{NT}=$ not tested

CoNS $=$ Coagulase-negative staphylococci 
tested except gentamicin and ceftriaxone ranged from $50 \%$ to $100 \%$.

No significant difference was found in the blood group of the blood in units contaminated by bacteria; blood group O positive $(9 / 79 ; 11.4 \%)$, blood group B positive $(3 / 33 ; 9.1 \%)$, blood group A positive $(1 / 17 ; 5.9 \%)$ and blood group $\mathrm{O}$ negative $(1 / 10 ; 10.0 \%)$ respectively.

The length of storage of the blood ranged from 0 to 21 days (mean $=4$ days); most contaminated samples $(57.1 \%)$ had $<1$ week of storage.

\section{Discussion}

The importance of the prevalence and source of bacterial contaminants of blood and blood components can not be over-emphasized particularly in the planning of preventive measures at blood transfusion centers across the world. In developed countries transfusion of blood and blood components has a low but known risk infection for patients, but remains a threat. ${ }^{10,11}$ Furthermore, the characterization of the bacterial isolates, types of blood or components contaminated and the antibiotic sensitivity pattern could be of public health importance and impact on clinical practice. The possibility and problem of bacterial contamination of blood and blood products has received very little attention in the African continent. Few countries in Africa; Ghana ${ }^{13,14}$ and perhaps Kenya have published records of bacterial contamination of blood or blood products. ${ }^{17}$ In the present study we report a prevalence of $8.8 \%$. This rate is lower than that reported from Ghana, a neighboring West African country, but comparable to the $8.8 \%$ found in paediatric whole blood transfusion from Kenya. ${ }^{17}$ Strikingly, it is higher than the rates $(0.2$ and $0.15 \%$ ) reported in the developed countries of United States $^{18}$ and UK ${ }^{19}$ respectively.

The observed high rate in our study as well as the other reports from Africa underscores the need for further laboratory and clinical surveillance of blood transfusions to be undertaken in adults and children to clarify the extent and nature of the problem. It also raises concerns on the need for improved measures to ensure blood transfusion safety. Efforts should be targeted towards altruistic repeat blood donors as against the replacement or paid donors that are common in our centers, ${ }^{20}$ in addition to improved donor selection and screening, and adequate cleaning of phlebotomy sites.

The bacterial isolates from this study are similar to those reported in the literature, ${ }^{13-15}$ these organisms generally proliferate poorly during storage at 1 to $6^{\circ} \mathrm{C}$. Being skin commensals, contamination is thought to occur primarily during phlebotomy, as a result of incomplete disinfection and/or skin core removal by the collection needle. ${ }^{21}$

Isolation of Listeria in blood products is unusual. Although widely distributed, it is rarely a commensal in humans. Interestingly enough all our three isolates occurred within a short time period. In 2004, the American Red Cross (ARC) of Southern California reported platelet products testing positive for Listeria monocytogens. ${ }^{22}$ About the same time, the Centre for Disease Control (CDC) found two other cases with the same pulse field gel electrophoretic patterns. Although the $\mathrm{CDC}$ report suggested that environmental contamination, false-positive laboratory results, and skin contamination are unlikely, we cannot completely exclude these factors in the present report as skin decontamination was done only with $70 \%$ alcohol. In line with the recent WHO guidelines for disinfection of phlebotomy sites, there is need to improve on skin disinfection for blood donors. ${ }^{23}$

As previously noted by Adjei et al, ${ }^{14}$ we found that contamination was usually evident within a week of blood donation. Gram-positive skin commensals are isolated soon after donation but rarely from stored blood, where as psychrotropic (cold-tolerating) Gramnegative organisms are not usually detectable until after a period of proliferation during storage. ${ }^{24}$

The high resistance rates in the organisms we isolated highlight the growing problem of antimicrobial resistance worldwide. ${ }^{25}$ It also portends grave concerns should septicaemia develop post-transfusion and require antimicrobial therapy.

The study is limited by the inability to follow up the recipients of the blood units to determine clinical outcome of infection, furthermore we had very small units of blood components - platelets, plasma to 
study. The rarity of other blood components is not unconnected with the small number of potential non-remunerated blood donors as well as scarcity of separating blood bags in the country.

\section{Conclusion and recommendations}

We conclude that bacterial contamination of transfused blood is common in our clinical practice. This portends a potential risk of hospital care associated infection to patients and with public health significance. The Nigerian National Blood Transfusion Policy introduced in 2006 should include protocols for prevention and control of donor blood contamination that can be adapted in transfusion centers across the country. Efforts have been made to ensure voluntary, unpaid donors, and we advocate the use of $70 \%$ alcohol with $2 \%$ chlorhexidine gluconate or tincture of iodine with for disinfecting phlebotomy sites, and of single-use towels for our blood bank units as recommended in the recent $\mathrm{WHO}$ guidelines. ${ }^{23}$

\section{Note}

This work was presented in part (orally) during the $1^{\text {st }}$ Infection Prevention Control African Network (IPCAN) congress in Kampala, Uganda 21-23, September, 2009.

\section{References}

1. Goodnough LT, Brecher ME, Kanter MH, et al. Transfusion medicine: blood transfusion. N Engl J Med 1999; 340: 438447.

2. Moore ACE, Dubbelman TMAR, Vansteveninck J, et al. Transfusion-transmitted diseases: risk, prevention and perspectives. Eur J Haematol 1999; 62: 1-18.

3. Cordonnier C. Infections after haemopoetic stem cell transplantation. In: EBMT handbook. eds. Apperley J, Carrerras E, Gluckman E, Gratwoul A and Masszi T. $5^{\text {th }}$ edition. 2008: pp 209-217.

4. Busch MP, Kleinman SH, Nemo G). Current and emerging infection risks of blood transfusion. JAMA 2003; 289: 959962.

5. Mabayoje VO, Oparinde DP, Akanni EO, et al. Seroprevalence of Hepatitis $B$ and $C$ and human immunodeficiency virus among blood donors in south-west Nigeria. Br J Biomed Sci 2007; 64: 177-179.

6. Erhabor O, Nwoka E, Adias TC. Seroprevalence of Treponema pallidum infection among blood donors in a resource-poor setting of the Niger Delta of Nigeria. African Sanguine 2007; 10: 19-21.

7. Dodd RY. Current viral risks of blood and blood components. Ann Med 2000; 32: 469-474.
8. Brecher ME, Shauna NH. Bacterial contamination of blood components. Clin Microbiol Rev 2005; 18: 195-204.

9. Blood Donor Recruitment. In: The National Blood Transfusion Policy; Federal Ministry of Health, Abuja, May 2006; 7-10.

10. Engekbreit $\mathrm{CP}$, Reesink HW, Blajchman MA et al. Bacterial contamination of blood components. Vox Sang 2008; 78: 59-67.

11. Hillyer CD, Josephson CD, Blajchman MA et al. Bacterial contamination of blood components; risks, strategies, and regulation. Joint $\mathrm{ASH}$ and $\mathrm{AABB}$ educational session in transfusion medicine. Hematology (Am Soc Hematol Educ Program) 2003; 575-589.

12. Hoppe PA. Interim measure for detection of bacterially contaminated red cell components. Transfusion 1992; 41: 1331-1334.

13. Opoku-Okrah C, Feglo P, Amidu $\mathrm{N}$ et al. Bacterial contamination of donor blood at the Temale teaching hospital, Ghana. Afr H Sci 2009; 9: 13-18.

14. Adjei AA, Kuma GK, Tettey $Y$ et al. Bacterial contamination of blood and blood components in three major transfusion centers, Accra, Ghana. Jpn J Infect Dis 2009; 62: 265-269.

15. Illert WE, Sanger W, Weise W. Bacterial contamination of single donor blood components. Transfus Med 1995; 5: 5761.

16. Clinical Laboratory Standards Institute. Performance Standards for Antimicrobial Susceptibility Testing; Eighteen Informational Supplement M100-S18. Wayne, PA: National Committee for Clinical Laboratory Standards; 2008;28(1).

17. Hassall O, Maitland K, Pole L et al. Bacterial contamination of paediatric whole blood transfusions in a Kenyan hospital. Transfusion 2009; 49: 2594-2598.

18. Kuehnert M, Roth VR, Haley NR et al. Transfusion transmitted bacterial infection in the United States, 1998 through 2000. Transfusion 2001; 42: 1493-1499.

19. Serious Hazard Of Transfusion. SHOT report for 2000-2001. 2002. (Cumulative data, 01/10/1995 to 30/09/2002).

20. Kotila TR, Fasola FA. Pattern of blood donation in a Nigerian tertiary hospital: the way forward. Africa Sanguine 2008; 11: 19-21.

21. Gibson T, Norris W. Skin fragments removed by injection needles. Lancet 1998; ii: 983-985.

22. Acute Communicable Disease Control 2004 Special Studies Report: Outbreak situation involving Listeria monocytogenes in platelets. http://www.lapublichealth.org/acd/reports/ spclrpts/2004/Listeria_SS04.pdf (Accessed 8th December, 2010).

23. WHO guidelines on drawing blood: best practices in phlebotomy http://whqlibdoc.who.int/publications/2010/ 9789241599221_eng.pdf (Accessed 8th December, 2010).

24. Depcik-Smith ND, Hay SN, Brecher ME. Bacterial contamination of blood products: factors, options, and insights. J Clin Apher 2001; 16: 192-201.

25. Okeke IN, Aboderin AO, Byarugaba DK et al. A disproportionate burden is placed on low-income people in Africa by the growing threat from multi-drug resistant enteric pathogens. Emerging Infectious Diseases 2007; 13: 1640 1646. 